\title{
Indicadores sociales en instituciones financieras de la Economía Popular y Solidaria
}

\section{Social Indicators in Financial Institutions of the Popular and Solidarity Economy}

\author{
Fabián Cajas Guerrero* \\ fcajasg@ups.edu.ec \\ Alberto Oña Serrano**
xavier.ona@epn.edu.ec \\ Odette Pantoja Díaz** \\ odettepantoja1980@gmail
}

\section{Resumen}

La presente investigación buscó conocer a través de un estudio de caso el análisis de todas las variables que se estructuran en el Balance Social, herramienta que ayudó en la determinación de la Responsabilidad Social de la institución, objeto de estudio de la Economía Popular y Solidaria. Cabe mencionar que el tipo de investigación utilizada tuvo un enfoque cualitativo y cuantitativo, además de estar apoyada en un trabajo de campo. Los resultados señalan que la responsabilidad asociativa y la política social interna de la Institución fueron calificadas escalarmente como buenas, con porcentajes significativos. No obstante, en relación a los canales de recepción de la información y la política educativa y la contribución para el desarrollo comunitario se presentaron resultados poco alentadores.

\section{Palabras clave}

Balance social, economía popular y solidaria, grupos de interés, rendición de cuentas, responsabilidad social corporativa.

* Ecuatoriano. Magister en Gerencia Empresarial con mención en Gestión de Proyectos. Universidad Politécnica Salesiana. Docente de Carrera de Administración de Empresas

** Ecuatoriano. Magister en Gerencia Empresarial con mención en Gestión de Proyectos. Escuela Politécnica Nacional. Docente-investigador.

*** Cubana. Estudiante de Doctorado en Universidad Politécnica de Valencia. Escuela Politécnica Nacional. Facultad de Ciencias Administrativas. Docente ocasional. 


\begin{abstract}
The present research searched to know, through a case study the analysis of all the variables that are structured in the Social Balance, a tool that helped in determining the Social Responsibility of the institution, object of study, of the popular and solidarity economy. It should be mentioned that the type of research used had a qualitative and quantitative approach, besides being supported in a field work. The results indicate that the associative responsibility and the internal social policy of the Institution were rated scalar as good, with significant percentages. However, in terms of the reception channels for information and educational policy and the contribution to community development, the results were not very encouraging.
\end{abstract}

\title{
Keywords
}

Accountability, corporate social responsibility, interest groups, popular and solidarity economy, social balance.

Forma sugerida de citar: Cajas Guerrero, Fabián, Oña Serrano, Alberto \& Pantoja Díaz, Odette (2016). Indicadores sociales en instituciones financieras de la Economía Popular y Solidaria. Retos, 12(2), pp. 133-148.

\section{Introducción}

En el Ecuador, según el Instituto de Economía Popular y Solidaria (IEPS), se considera que el $64 \%$ del empleo nacional por subsector económico es generado por la Economía Popular y Solidaria (EPS), además la diversificación de sus productos y derivados es fundamental para potenciar el cambio de la nueva Matriz Productiva en el país, así como establecer estrategias para la erradicación de la pobreza como elementos claves para dar cumplimiento al PNBV 2013-2017. Desde este contexto, es fundamental analizar la participación que tiene el sector de la EPS en el sistema económico y financiero del Ecuador (Cardoso et al., 2012).

La EPS es una forma de organización económica en la que sus integrantes, ya sea individual o colectivamente:

Organizan y desarrollan procesos de producción, intercambio, comercialización, financiamiento y consumo de bienes y servicios mediante relaciones basadas en la solidaridad, cooperación y reciprocidad, situando al ser humano como sujeto y fin de su actividad (LOEPS, 2011). 
Así, aquellas formas de organización se agrupan bajo dos sectores: el real de la EPS (Sector no Financiero) y el SFPS (Sector Financiero). En el marco de la Economía Social y Solidaria, el Sistema Financiero Popular y Solidario (SFPS) es de trascendental importancia, pues constituye un mecanismo de organización y participación de los actores y sujetos sociales de la Economía Popular Solidaria en el Sistema Financiero (CONAFIPS, 2012).

Por lo indicado anteriormente, es fundamental el paso dado en el Ecuador al incorporar las Finanzas Populares y Solidarias en su Constitución del 2008, conforme establecen los artículos 308 al 312 (Asamblea Constituyente, 2014; Registro Oficial, 2014).

En la actualidad son pocas las instituciones que implementan y gestionan la Responsabilidad Social como un objetivo estratégico a fomentar, convirtiéndose en una necesidad de alta prioridad su gestión, considerando la problemática existente de vital importancia el desarrollar las directrices trazadas por el PNVB en instituciones ecuatorianas. Considerando esta problemática existente, la presente investigación se enmarca en el análisis de la Responsabilidad Social de una Institución Financiera de la Economía Popular y Solidaria.
Por lo que este estudio responde a la pregunta ¿Cuál es el nivel de compromiso de las instituciones financieras de la Economía Popular y Solidaria con la Responsabilidad Social?

\section{Modelos de Balance Social: Mo- delo de balance social según la Organización Internacional del Trabajo (OIT)}

Constituye una herramienta para la planificación, organización, dirección, registro, control y evaluación de la gestión social (Manrique, 2013), se encuentra integrado de manera general por dos áreas: interna y externa (Peralta \& Pineida, 2015). El área interna está compuesta por el ámbito socio-laboral, los servicios sociales, la integración y desarrollo. En el caso del área externa lo componen las relaciones primarias, las relaciones con la comunidad y las relaciones con otras instituciones (Martínez, 2014; Carrizo, 2010).

\section{Modelo de balance social según el Global Compact de Naciones Unidas}

El Pacto Global de las Naciones Unidas se crea con la finalidad de garantizar la responsabilidad global de las empresas (Alcaraz \& Rodenas, 2013) y está compuesto por cuatro ejes bases y diez principios (Patiño, 2011). En su metodología abarca indicadores cualitativos, los cuales 
representan su importancia dentro del modelo de balance social.

Modelo de balance social según el Global Reporting Initiative (GRI)

Es el más utilizado por las empresas en aras de medir la sustentabilidad corporativa, evidenciándose en los últimos años un incremento en la emisión de reportes por parte de las entidades (González et al., 2015); conocidas como las directrices encaminadas a desarrollar reportes voluntarios de sustentabilidad a nivel mundial (Brown, 2011; Planken, 2013; Dingwert \& Eichinger, 2010). Se cimienta en los tres elementos del desarrollo sostenible, los cuales son económico, social y medioambiente (Viteri \& Jácome, 2013; García et al., 2011).

\section{Modelo de balance social según el Instituto ETHOS}

Enfoca la Responsabilidad Social Corporativa como una manera de gestionar las empresas logrando que las mismas sean responsable del desarrollo social y ambiental (de Oliveira \& Abadía, 2013). Esta norma permite la gestión empresarial ya que los indicadores posibilitan la evaluación del grado de "desarrollo de las estrategias, políticas y prácticas en los ámbitos que involucran la responsabilidad social de una organización" (Giménez et al., 2010, p. 42).
Modelo de balance social según la Alianza Cooperativa Internacional $(\mathrm{ACI})$

El Balance Social Cooperativo ha sido promovido con bastante fuerza en los últimos tiempos gracias a la promoción de varios grupos y entidades, dentro de los que destaca la ACI (Ressel \& Coppini, 2012). Los siete principios de la ACI están basados en membresía abierta y voluntaria; control democrático de miembros; participación económica de los miembros; autonomía e independencia; educación, formación e información; cooperación entre cooperativas y compromiso con la comunidad (Martínez, 2014; Ortega \& Ortiz, 2011).

\section{Modelo de balance social según} la metodología de la SEPS

Se basa en la integración de los siete principios de la ACI (mencionados con anterioridad), los diez Principios del Buen Vivir:

- Unidad en la diversidad

- Ser humano que desea vivir en sociedad

- Igualdad, integración y cohesión social

- Cumplimiento de derechos universales y la potenciación de las capacidades humanas

- Relación armónica con la naturaleza 
- Convivencia solidaria, fraterna y cooperativa

- Trabajo y ocio liberadores

- Reconstrucción de lo público

- Democracia representativa, participativa y deliberativa

- Estado democrático, pluralista y laico

Y los ocho principios de la LOEPS:

- Búsqueda del Buen Vivir y del Bien Común

- Prelación del trabajo sobre el capital y los intereses colectivos sobre los individuales

- Comercio justo, ético y responsable

- Equidad de género

- Respeto a la identidad cultura

- Autogestión

- La responsabilidad social y ambiental, la solidaridad y rendición de cuentas; y,

- La distribución equitativa y solidaria de excedentes (Páez, 2013).

\section{Metodología}

Las técnicas de investigación, medios y herramientas para acceder a la información, permitieron establecer, entre otras cosas, el nivel de conocimiento por parte de los socios de la Institución sobre el tema de la Responsabilidad Social, en este sentido, se aplicó en Julio de 2015 un cuestionario que fue vali- dado por funcionarios de la institución y por expertos conocedores del tema; los datos fueron procesados en el programa estadístico informático SPSS v.21.0 el mismo que permite procesar la información y presentar tablas y gráficos estadísticos.

Se consideró para el estudio una muestra de 400 socios de las nueve agencias de la entidad en la ciudad de Quito con edades comprendidas entre 25 y 65 años. Se decidió realizar la investigación dirigida a los socios porque una vez obtenidos los resultados permitan difundir entre ellos estrategias de mejora y se constituyan en una transparente rendición de cuentas por parte de los directivos de la institución.

La encuesta contó de diez preguntas cerradas, en las cuales se les consultó el cumplimiento de aspectos cualitativos de la entidad relacionados con el ámbito social, económico y ambiental; a continuación, se citan las más relevantes: ¿Cuál es el grado de conocimiento de los deberes y derechos que tiene como socio de la entidad? ¿Qué le parece la tasa de interés establecida por la institución para los depósitos a plazos? ¿Qué opinión le merece los servicios sociales (salud, alimentación y educación) que le brinda la institución? ¿Qué opinión tiene sobre la contribución que realiza la entidad para el desarrollo de la comunidad y la protección del me- 
dio ambiente? Adicionalmente se consolidó el estudio utilizando las Macrodimensiones y Dimensiones a través de la medición y comparación de indicadores cualitativos y cuantitativos de acuerdo a lineamientos tipificados en el modelo de Balance Social de la SEPS.
En relación al tamaño de la población, se definió la misma en 87.751 socios y clientes activos correspondiente a las agencias de la Institución en la ciudad de Quito durante el año 2014 como se observa en la Tabla 1.

Tabla 1. Número de socios y clientes activos de la Institución

\begin{tabular}{|c|c|c|c|c|}
\hline $\begin{array}{c}\text { Cód. } \\
\text { Región }\end{array}$ & $\begin{array}{c}\text { Cód. } \\
\text { Agencia }\end{array}$ & Agencias & $\begin{array}{c}\text { Núm. Cuentas } \\
\text { Activas Socios }\end{array}$ & $\begin{array}{c}\text { Núm. Cuentas } \\
\text { Activas Clientes }\end{array}$ \\
\hline 1 & 1 & Agencia 1 & 21864 & 3695 \\
\hline 1 & 9 & Agencia 2 & 8789 & 1774 \\
\hline 1 & 19 & Agencia 3 & 5674 & 809 \\
\hline 1 & 36 & Agencia 4 & 6359 & 1248 \\
\hline 1 & 40 & Agencia 5 & 4690 & 1223 \\
\hline 1 & 41 & Agencia 6 & 14063 & 3313 \\
\hline 1 & 42 & Agencia 7 & 4042 & 1946 \\
\hline 1 & 44 & Agencia 8 & 1862 & 1264 \\
\hline 1 & 45 & Agencia 9 & 3521 & 1615 \\
\hline & & Total & 70864 & 16887 \\
\hline
\end{tabular}

Fuente: Elaboración propia

Para la determinación de la de acuerdo a la Tabla 2. El levantamuestra se aplicó la fórmula para po- miento de la información se realizó blación finita, con un margen de error en el mes de julio del año 2015, dude $+/-5 \%$ y nivel de confiabilidad del rante una semana, en horas labora95\%, lo que arrojó como tamaño bles y al ingreso de las agencias de la muestral la cantidad de 400 encuestas Institución de la ciudad de Quito.

$$
\begin{aligned}
& n=\frac{Z_{\alpha^{2}} p q N}{E^{2}(N-1)+Z_{\alpha^{2}} p q} \\
& n=\frac{(1.96)^{2}(0.5)(0.5)(87.751)}{(0.05)^{2}(87.751-1)+(1.96)^{2}(0.5)(0.5)}=400
\end{aligned}
$$


Tabla 2. Variables para el cálculo del tamaño de la muestra

\begin{tabular}{|l|l|}
\hline \multicolumn{1}{|c|}{ Variable } & \multicolumn{1}{|c|}{ Valor } \\
\hline Tamaño de la población N (socios) & 87751 \\
\hline Probabilidad que el evento p ocurra & 0.5 \\
\hline Probabilidad que el evento q no ocurra & 0.5 \\
\hline Nivel de confianza (alfa) & $95 \%$ \\
\hline Valor crítico correspondiente al nivel de confianza elegido (Z) & 1.96 \\
\hline Margen de error permitido [E] & $5 \%$ \\
\hline Tamaño de la muestra (n) & 400 \\
\hline
\end{tabular}

Fuente: Elaboración propia

\section{Resultados}

Encuestas a socios externos de la ferente al grado de conocimiento institución en las agencias en Quito de los derechos y obligaciones que De los datos recopilados, en la tiene como socio de la entidad, lo Figura 1 se observa la pregunta re- califican el 47\% como bueno y el $19 \%$ como muy bueno.

Figura 1. Responsabilidad asociativa

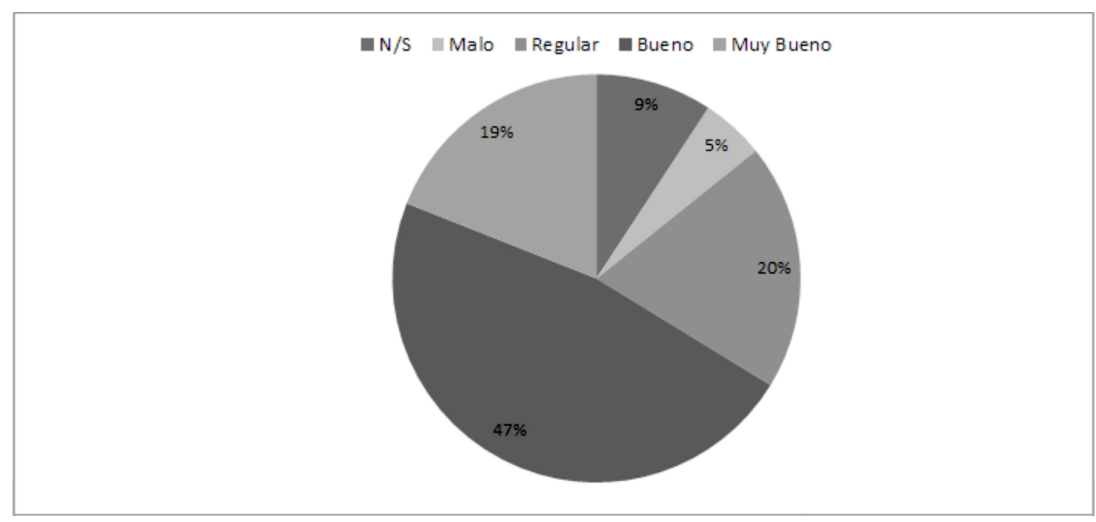

Fuente: Elaboración propia

Como se muestra en la Figura 2, a pesar de que la Institución se esfuerza en brindar información a sus socios, el $75 \%$ desconoce sobre lo que significa la Asamblea Gene- ral de Socios, en igual proporción no saben sobre temas tratados en los Consejos de Administración vinculados con proyectos, decisiones, etc. 
Figura 2. Conocimiento sobre la Asamblea General de socios

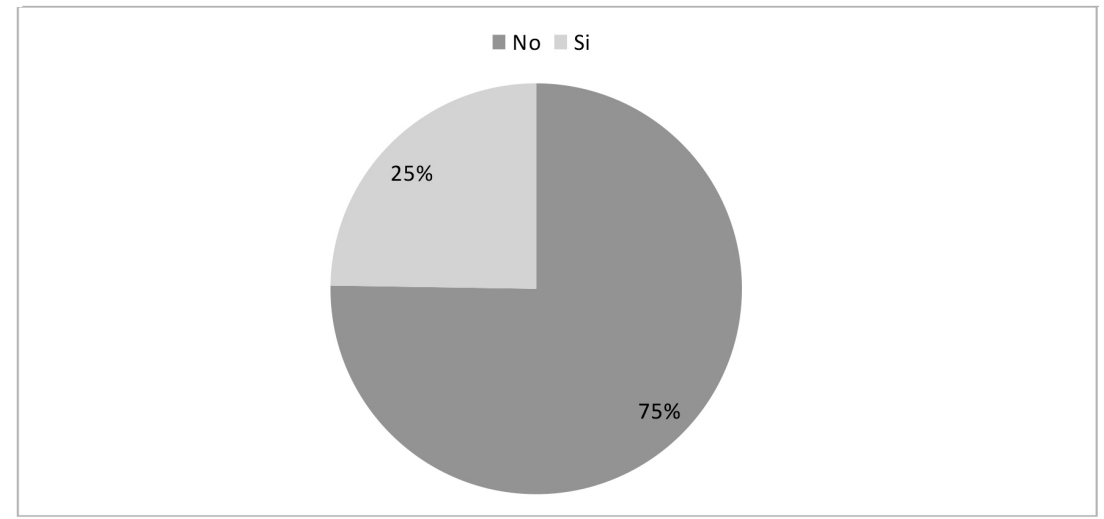

Fuente: Elaboración propia

En relación a los canales de re- través de medios formales, esto es: cepción de la información por parte anuncios escritos, memos, reuniode los socios, se indica que un $36 \%$ nes informativas, entre otros, como no conoce sobre la marcha de la se indica en la Figura 3. Institución y un $27 \%$ lo obtiene a

Figura 3. Canales de recepción de la información

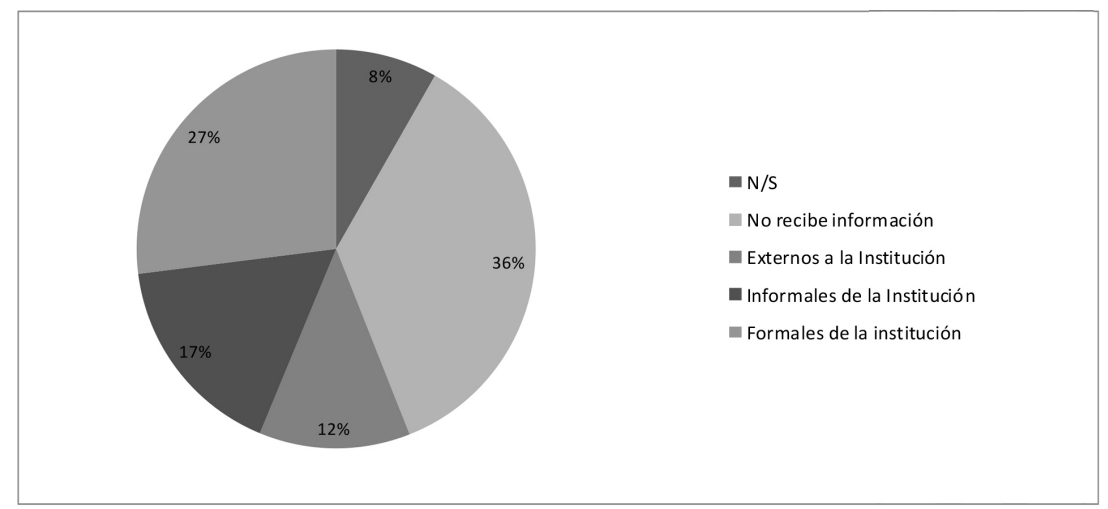

Fuente: Elaboración propia

Como lo muestra la Figura 4, referente a los servicios sociales que la entidad les brinda a sus socios, tales como alimentación, salud, se- guros, etc., comparados con otros similares ofrecidos en el mercado, se concluyó que a pesar de que un $32 \%$ de los encuestados no conocen sobre 
la prestación de estos servicios, la mayor parte lo califican en general como bueno con un $37 \%$ a la calidad del servicio ofrecido por la misma.

Figura 4. Calificación de los servicios sociales

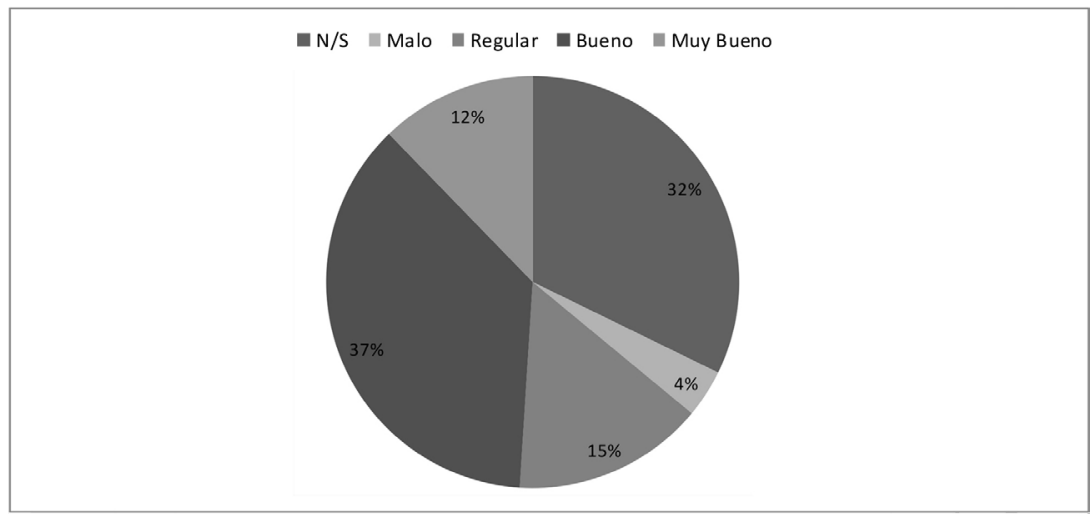

Fuente: Elaboración propia

Dentro de la política educativa y la contribución para el desarrollo comunitario por parte de la Institución para sus socios, relacionadas con actividades de educación, capacitación e información; se investigó que el $54 \%$ de los encuestados no saben sobre la existencia de actividades educativas, culturales y deportivas, en la Figura 5 se indica que el $37 \%$ desconocen sobre las actividades vinculadas con la comunidad y la protección del medio ambiente.

Figura 5. Desarrollo de la Comunidad y medio ambiente

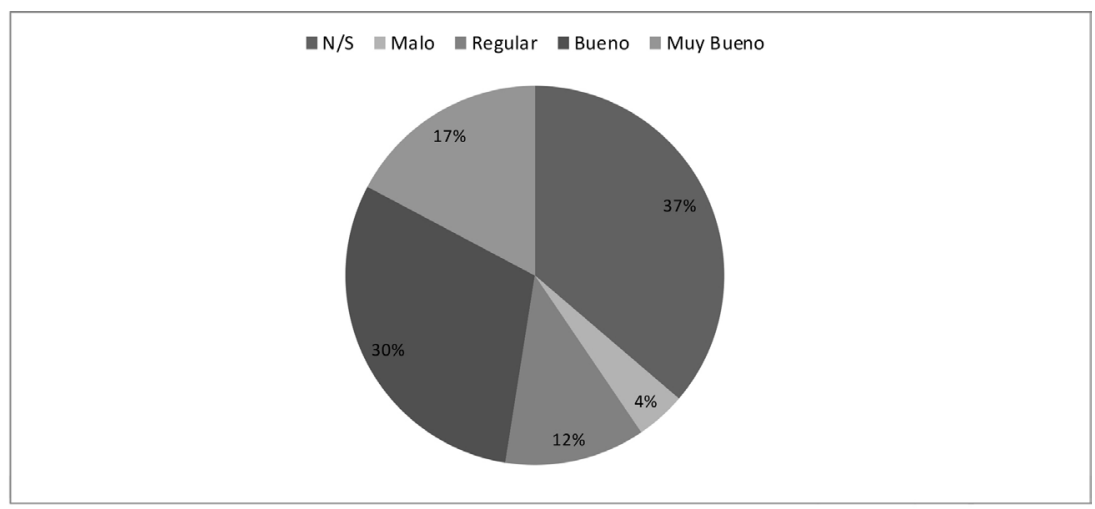

Fuente: Elaboración propia 
Es importante mencionar que en función de los principios del modelo de balance social ecuatoriano, las dimensiones subyacen en las Macrodimensiones, en este sentido se expondrán los resultados más relevantes de las Dimensiones:

En la figura 6, entre el año 2013 y 2014, expresa que se gene- raron 95 nuevas plazas de trabajo. Para el año 2013 la población de trabajadores de la entidad fue de 459 empleados y para el año 2014 fue de 554 empleados, lo que determina que desde el año 2013 al 2014 la generación de empleos nuevos se incrementó en un 21\%.

Figura 6. Indicador empleos generados

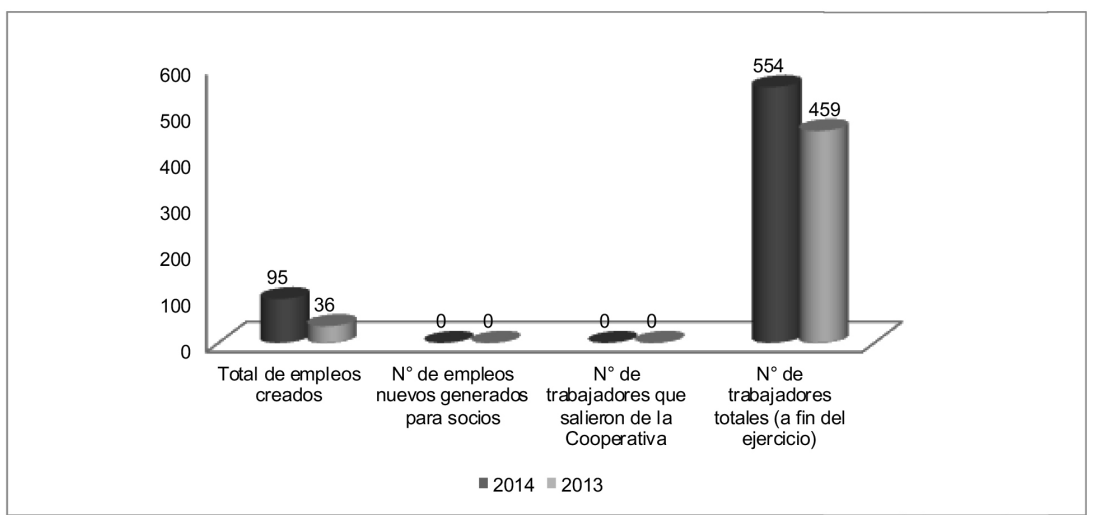

Fuente: Elaboración propia

El indicador Rotación y Estabilidad Laboral refleja como aspecto relevante la medición del clima laboral dentro de la institución, el cual fue adecuado, pues, en el año 2014 y de acuerdo a datos proporcionados por la entidad, representó en promedio el $80 \%$, tomando en cuenta factores internos de evaluación como: compromiso con el cliente, condiciones de trabajo, relaciones interpersonales, desarrollo y capacitación, productividad, retos y oportunidades, entre otros; esto evidenció un aumento en la generación de empleos nuevos en un $21 \%$, así mismo, el indicador estabilidad laboral evaluado en la participación de género en la institución indicó que el número de trabajadores hombres aumentó en $29,4 \%$ y el número de trabajadores mujeres se incrementó en $14,7 \%$, de esta forma, en el año 2014 la distribución correspondió a $56 \%$ mujeres y $44 \%$ hombres. 
La Figura 7, indica los datos relacionados a los servicios de salud entregados a los socios por parte de la Institución durante el período de estudio, 2013-2014. Este indicador está relacionado con los montos referentes a Programas de salud (preventiva y prepagada) con un incremento del
3\%; Programas de bienestar social entregados a socios, clientes y sus familiares por seguros con un incremento del 2,8\%; reembolsos cubiertos por servicios médicos y odontológicos con un incremento del $18,4 \%$ y Programas de seguro exequial con un aumento del 45,3\%.

Figura 7. Indicador programas de salud

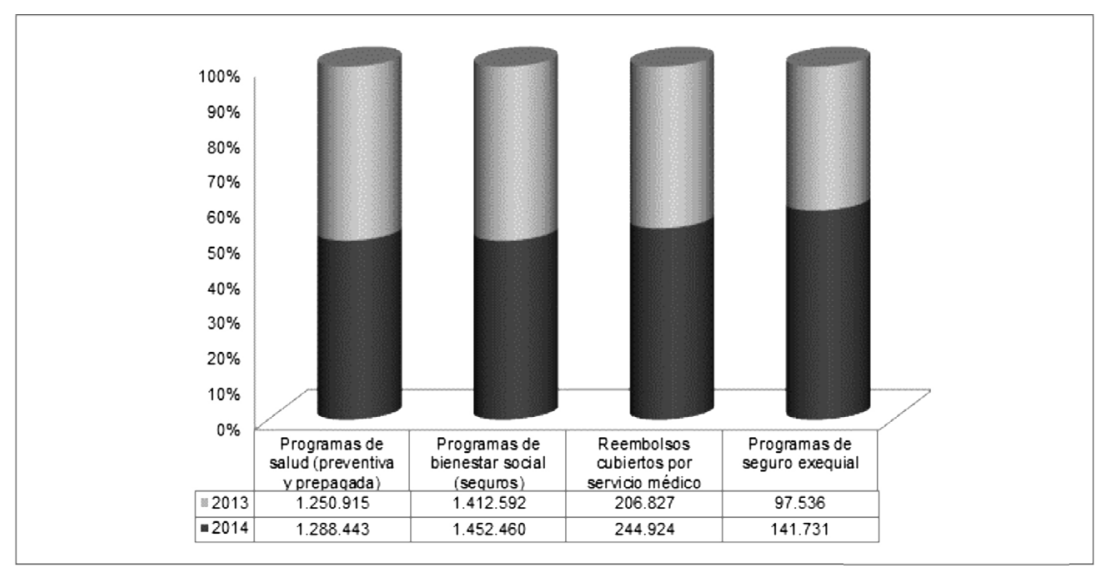

Fuente: Elaboración propia

Como lo muestra la Figura 8, la participación económica, solidaria y distribución equitativa medida a través del Indicador Valor Agregado Cooperativo (VAC) correspondiente al año 2014, indica cómo se reparte dicho valor entre los diferentes involucrados, los Trabajadores a través de sus salarios y otros beneficios sociales representa el 70\%, los Socios el 15\%, la Comunidad el 9\%, el Sector Financiero el 4\% y el Patrimonio Común el 2\%. En la investigación se llegó a determinar que existe una variación del VAC, entre el período 2014 y 2013, donde el valor distribuido a los trabajadores $(70 \%$ y $62 \%)$ respectivamente tiene una disminución del 0,4\% reflejados en sus salarios y otros beneficios sociales concedidos, el valor distribuido a la comunidad con un incremento del $19,1 \%$ (9\% y $6 \%$ ) y el valor distribuido a los socios con una variación del 41,8 \% manifestado a través de la repartición de sus excedentes y representan el 15\% y $23 \%$ respectivamente. 
Figura 8. Indicador Valor Agregado Cooperativo

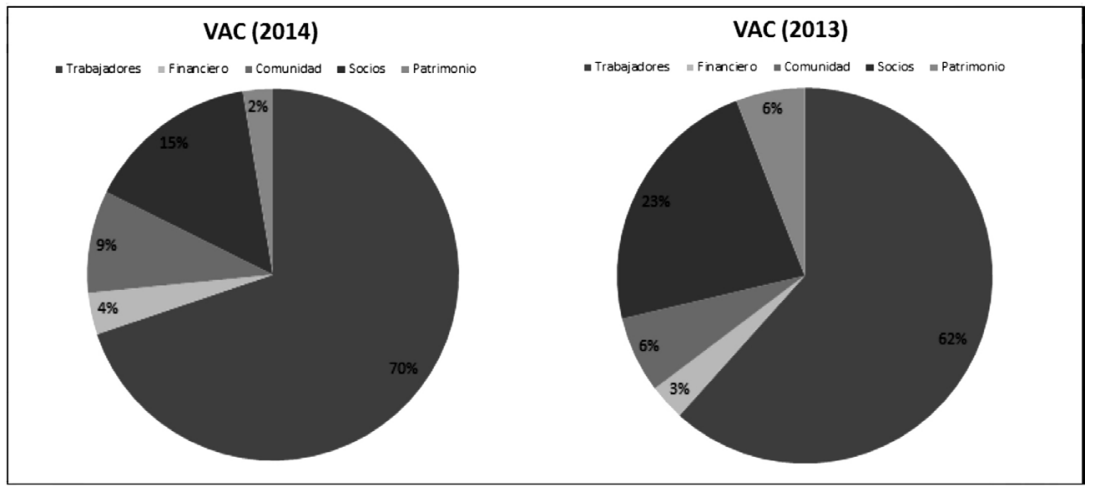

Fuente: Elaboración propia

Con respecto al indicador inversiones en capacitación se puede mencionar que el presupuesto es variable en cada período, en el período en estudio hay una disminución del $11 \%$ en los gastos destinados a capacitación de los trabajadores; es un factor a tomar en cuenta por la Institución; en relación a los gastos destinados a capacitación de Directivos ha habido un aumento del 111\%. Otro aspecto a tomar en cuenta es el cumplimiento del presupuesto para este rubro, pues el año 2013 se cumplió en un 85\%, mientras que el año 2014 el 51\%, dando como resultado una disminución del 40\% entre los períodos indicados.

Comparativa con estudio desarrollado por la Superintendencia de Economía Popular y Solidaria (SEPS)

La SEPS desarrolló una investigación basada igualmente en las Macrodimensiones del Balance social de las organizaciones de la Economía Popular y Solidaria ecuatorianas (SEPS, 2015). A continuación se contrastan los resultados de dicho estudio con los de la presente investigación.

Relativo a la Macrodimensión de la prelación del trabajo sobre el capital, en la dimensión de rotación y estabilidad laboral, según la SEPS (2015) la mayor parte de las organizaciones no analizan este indicador (36\%), seguido por una mayoría del $28 \%$ que contrarresta los efectos de esta rotación a través del incremento salarial. En el presente estudio en contraposición se apreció que este indicador si es considerado en las instituciones financieras analizadas, reflejándose en la existencia de un clima laboral adecuado con un índice elevado del $80 \%$. Esto constituye un indicativo de que si se ges- 
tionan elementos relacionados a las condiciones de trabajo y relaciones interpersonales.

$\mathrm{Al}$ analizar la dimensión de la prelación de los intereses colectivos sobre los individuales, se pudo identificar que según la investigación de la SEPS (2015), el 59\% de los encuestados no tratan este tema, seguidos del $23 \%$ que proporcionan a sus asociados planes de beneficio colectivo. En este contexto, se podría inferir, en función de la información entregada por la Institución objeto de estudio, que estaría vinculada al segundo segmento.

Referente a la Macrodimensión de utilización de utilidades y excedentes, la SEPS (2015) dictamina que la mayor parte de las cooperativas distribuyen sus utilidades y excedentes solamente considerando las disposiciones legales. En el caso de las instituciones financieras, el presente estudio detectó que a pesar que el valor distribuido a los trabajadores es elevado (70$62 \%)$ se nota una disminución del mismo; al igual que se identificó un incremento en el valor distribuido a la comunidad.

Según la SEPS (2015), la Macrodimensión de educación, capacitación y comunicación en la mayor parte de las cooperativas existe un plan de formación, aunque no disponen para su ejecución de partida presupuestaria. En la presente investigación se detectó un comportamiento contradictorio en las instituciones financieras abordadas, las cuales a pesar de que si cuentan con un presupuesto para estas acciones, han sufrido disminuciones en los gastos de las capacitaciones enfocadas a los trabajadores, contrario a que se han incrementado las capacitaciones destinadas a los directivos. Igualmente la no ejecución presupuestaria de este rubro es otra dolencia que padecen dichas organizaciones.

Respecto a la Macrodimensión relacionada con la comunidad y el compromiso social, la SEPS (2015) detecta que en su mayoría las organizaciones no abordan estos temas. Por otra parte, según el presente estudio se constató que a pesar de que esta Macrodimensión si es gestionada por las instituciones financieras, existe una tendencia a la disminución reflejándose en los decrementos asociados a donaciones destinadas a actividades socioculturales, créditos de consumo, de viviendas y urbanos.

\section{Conclusiones}

Es fundamental la importancia que representa la Responsabilidad Social en una organización, porque se constituye en una nueva visión dentro del ámbito de la gestión social, cuyo propósito principal es mejorar sustancialmente las actuaciones tradicionales y asumir com- 
promisos no sólo en lo interno con los trabajadores, sino también en lo externo en la vinculación con la comunidad y medio ambiente.

Los factores que se tomaron en cuenta para determinar el diagnóstico de la Responsabilidad Social de la Institución, lo constituyeron: a) aspectos relacionados con el sustento teórico de la RSC; b) el marco institucional y el fundamento legal; c) la identificación de los grupos de interés de la Institución y d) la descripción, metodología y análisis de la herramienta de gestión, el Balance Social.

El proceso metodológico del Balance Social que actualmente utiliza la Institución, valida lineamientos de los siete principios universales del cooperativismo establecidos por la Alianza Cooperativa Internacional, puesto que revisan el grado de accesibilidad para nuevos socios; la participación democrática y económica de los miembros; la autonomía en su administración, la educación y capacitación a los socios, representantes elegidos, directivos y trabajadores; el grado de interacción con otras Instituciones y su compromiso con la comunidad tanto interna como externa de la entidad.

Los indicadores más significativos a través del análisis de las Macrodimensiones para el cumplimiento del Balance Social en el año 2014, contrastaron los resultados y se evi- denció la evolución de los mismos determinados en las dimensiones del desempeño social, económico y medioambiental de la Institución.

\section{Bibliografía}

Alcaraz, A., \& Rodenas, S. (2013). The Spanish Banks in face of the Corporate Social Responsibility Standards: previous analysis of the financial crisis. Revista Brasileira de Gestao de Negocios, 15(49), 562.

Asamblea Constituyente (2014). Constitución de la República del Ecuador, Quito - Ecuador: Registro Oficial. vol. 449, 10-20.

Brown, H. (2011). Global reporting initiative. Handbook of Transnational Governance: Institutions \& Innovations. Polity Press, 281289. Cambridge, UK.

Cardoso, G., Bermeo, E., \& Fresa, M. (2012). Ecuador: economía y finanzas populares y solidarias, para el buen vivir. Programa Nacional de Finanzas Populares, Emprendimiento y Economía SolidariaPNFPEES Secretaría Nacional del Migrante-SENAMI Programa de las Naciones Unidas para el Desarrollo-PNU. Quito: Imprefepp.

Carrizo, G. C. (2010). Informes contables de Responsabilidad Social Empresarial. Gestión Joven, 5(5).

CONAFIPS (2012). Economía y finanzas populares y solidarias para el Buen Vivir. Programa Nacional de Finanzas Populares, Emprendimiento y Economía Solidaria.

de Oliveira, M. L., \& Abadía, M. M. (2013). El desempeño económi- 
co financiero y responsabilidad social corporativa Petrobrás versus Repsol.Contaduría y administración. 58(1), 131-167.

Dingwert, K., \& Eichinger, M. (2010). Tamed transparency: How information disclosure under the Global Reporting Initiative fails to empower. Global Environmental Politics, 10(3), 74-96.

García, J., Iturrioz del Campo, J., Gordon, M., \& Palomo, R. (2011). La percepción sobre la responsabilidad social en las sociedades cooperativas de trabajo asociado y las sociedades laborales: un análisis en el ámbito de la ciudad de Madrid. REVESCO. Revista de Estudios Cooperativos, 104, 102-124.

Giménez, G., Gómez, J., \& Villegas, M. (2010). La responsabilidad social en las organizaciones (RSO): análisis y comparación entre guías y normas de gestión e información. Innovar. Innovar, 17(29), 27-48.

González, M., del Mar Alonso, M., Avila, C., \& Domínguez D. (2015). Modeling sustainability report scoring sequences using an attractor network. Neurocomputing, 168, 1181-1187.

LOEPS (2011). Ley Orgánica de la Economía Popular y Solidaria. Superintendencia de Economía Popular y Solidaria.

Manrique, O. J. (2013). Evidencia de los elementos de la responsabilidad social empresarial en los modelos de la gerencia administrativa y propuesta para mejorar la práctica de la responsabilidad social empresarial.

Martínez, P. C. (2014). Elaboración del Balance Social caso: Cooperati- va de Ahorro y Crédito Frente de Reivindicación del Magisterio del Austro.(Tesis de pregrado). Universidad Politécnica Salesiana. Cuenca, Ecuador.

Ortega, C., \& Ortiz, M. (2011). ¿Cómo aplican las sociedades cooperativas de éxito los principios cooperativos? El caso del Grupo Hojiblanca. CIRIEC-España, Revista de Economía Pública, Social y Cooperativa, 72, 156-185.

Páez, J. R. (2013). Serie Estudios sobre Economía Popular y Solidaria. SEPS. Intendencia de Estadísticas, Estudios y Normas de la EPS y SFPS. Quito: V\&M Gráficas.

Patiño, D. P. (2011). El Pacto Global de las Naciones Unidas: sobre la responsabilidad social, la anticorrupción y la seguridad. Revista Prolegómenos. Derechos y Valores de la Facultad de Derecho, 4(28).

Peralta, A., \& Pineida, R. (2015). Diseño de un modelo de balance de rendición de cuentas para determinar la responsabilidad social de la Cooperativa de Ahorro y Crédito del Distrito Metropolitano de Quito "Amazonas". (Trabajo de titulación previa a la obtención del título de Ingenieras Comerciales). UPS.

Planken, B. (2013). Global Reporting Initiative. Encyclopedia of Corporate Social Responsibility, 12541256.

Registro Oficial (2014). Código Orgánico Monetario y Financiero. Asamblea Nacional. República del Ecuador, Quito.

Ressel, A. B., \& Coppini, V. (2012). El balance social y su importancia como instrumento de medición 
en las organizaciones de la economía social, particularmente en las cooperativas. En: VII Congreso Internacional Rulescoop-Economía social: identidad, desafíos y estrategias.Valencia-Castellón, España.
SEPS (2015). Rendición de Cuentas 2014. Superintendencia de Economía Popular y Solidaria. Quito.

Viteri, J., \& Jácome, M. (2013). La Responsabilidad Social como modelo de gestión empresarial. EIDOS, 4, 92-100.

Recepción: 02-29- 2016 - Aceptación: 12-04- 2016. 